\title{
What We Are Watching-Top Global Infectious Disease Threats, 2013-2016: An Update from CDC's Global Disease Detection Operations Center
}

Kira A. Christian, A. Danielle Iuliano, Timothy M. Uyeki, Eric D. Mintz, Stuart T. Nichol, Pierre Rollin, J. Erin Staples, and Ray R. Arthur

To better track public health events in areas where the public health system is unable or unwilling to report the event to appropriate public health authorities, agencies can conduct event-based surveillance, which is defined as the organized collection, monitoring, assessment, and interpretation of unstructured information regarding public health events that may represent an acute risk to public health. The US Centers for Disease Control and Prevention's (CDC's) Global Disease Detection Operations Center (GDDOC) was created in 2007 to serve as CDC's platform dedicated to conducting worldwide event-based surveillance, which is now highlighted as part of the "detect" element of the Global Health Security Agenda (GHSA). The GHSA works toward making the world more safe and secure from disease threats through building capacity to better "Prevent, Detect, and Respond" to those threats. The GDDOC monitors approximately 30 to 40 public health events each day. In this article, we describe the top threats to public health monitored during 2012 to 2016: avian influenza, cholera, Ebola virus disease, and the vector-borne diseases yellow fever, chikungunya virus, and Zika virus, with updates to the previously described threats from Middle East respiratory syndromecoronavirus (MERS-CoV) and poliomyelitis.

Keywords: Surveillance, Infectious diseases, Epidemic management/response, Avian influenza, Viral hemorrhagic fevers

Kira A. Christian, DVM, is a Veterinary Medical Epidemiologist, and Ray R. Arthur, PhD, is Director; both in the Global Disease Detection Operations Center, Emergency Response and Recovery Branch, Division of Global Health Protection, Center for Global Health, Centers for Disease Control and Prevention (CDC), Atlanta, GA. A. Danielle Iuliano, PhD, is a Senior Research Epidemiologist, and Timothy M. Uyeki, MD, is a Medical Epidemiologist; both in the Epidemiology and Prevention Branch, Influenza Division, National Center for Immunization and Respiratory Diseases, CDC, Atlanta, GA. Eric D. Mintz, MD, is a Medical Epidemiologist, Waterborne Diseases Prevention Branch, Division of Foodborne, Waterborne, and Enteric Diseases, National Center for Emerging and Zoonotic Infectious Diseases, CDC, Atlanta, GA. Stuart T. Nichol, PhD, is Chief, and Pierre Rollin, MD, is Team Lead; both in the Viral Special Pathogens Branch, Division of High-Consequence Pathogens and Pathology, National Center for Emerging and Zoonotic Infectious Diseases, CDC, Atlanta, GA. J. Erin Staples, MD, PhD, is Medical Officer, Arboviral Diseases Branch, Division of Vector-Borne Diseases, National Center for Emerging and Zoonotic Infectious Diseases, CDC, Ft. Collins, CO. The findings and conclusions in this report are those of the authors and do not necessarily represent the official position of the Centers for Disease Control and Prevention.

(C) Kira A. Christian et al., 2017; Published by Mary Ann Liebert, Inc. This Open Access article is distributed under the terms of the Creative Commons Attribution Noncommercial License (http://creativecommons.org/licenses/by-nc/4.0/) which permits any noncommercial use, distribution, and reproduction in any medium, provided the original author(s) and the source are credited. 
$\mathrm{D}$ ETECTING, REPORTING, AND RESPONDING to significant public health events occurring in areas where the public health system is unable or unwilling to report the event to appropriate public health authorities is a constant challenge for those monitoring global disease activity. To better track public health events in these situations, agencies can conduct event-based surveillance, which is defined as the organized collection, monitoring, assessment, and interpretation of unstructured information regarding public health events that may represent an acute risk to human health. ${ }^{1}$ When conducting event-based surveillance, information can be collected through formal channels, such as already-established public health surveillance systems; in such instances, event-based surveillance can be complementary to indicator- or case-based surveillance systems that collect information on individual cases rather than events. Event-based surveillance can also be conducted through informal channels, such as through monitoring media reports, blogs, or even social media. Because events reported through informal channels commonly involve unconfirmed media reports, they must be verified before any action is taken.

In 2004, the US Congress authorized an appropriation of funding to establish a global disease detection program based at the Centers for Disease Control and Prevention (CDC), and in 2007, the Global Disease Detection Operations Center (GDDOC) was created to serve as CDC's platform dedicated to conducting worldwide event-based surveillance. Surveillance, including event-based surveillance, is now being highlighted as part of the "detect" element of the Global Health Security Agenda (GHSA), launched in 2014, which works toward making the world more safe and secure from disease threats through building capacity to better "Prevent, Detect, and Respond" to those threats. Capacity to "detect" disease threats is built by establishing and strengthening global networks for real-time biosurveillance; strengthening rapid, transparent reporting and laboratory sample sharing; strengthening laboratory systems; and deploying an effective biosurveillance workforce. ${ }^{2}$ Facilitating detection is the Biosurveillance Indications and Warning Analytic Community (BIWAC), which is a self-organized, informal biosurveillance informationsharing group with participants from multiple US government agencies. The BIWAC shares data via unsophisticated web interfaces (eg, password-protected internet interface) and has focused on interagency collaboration and partnership. ${ }^{3}$ A key member of the BIWAC is the Armed Forces Health Surveillance Branch (AFHSB), which also houses the Global Emerging Infections Surveillance and Response System (GEIS). ${ }^{4}$ Pre-dating the GDDOC, GEIS was created in 1997 to provide a mechanism in the Department of Defense (DoD) to centralize coordination of surveillance efforts conducted by the $\mathrm{DoD}$, including outbreak response, epidemiologic training and capacity building, and the support of research and innovation in the US military and partner organizations. ${ }^{4}$ The GDDOC has a team of 6 staff and a director with professionally diverse backgrounds, including epidemiology, microbiology, and human, veterinary, and tropical medicine; it is situated in dedicated space located in CDC's Emergency Operations Center (EOC), with which the GDDOC liaises both during GDDOC-supported international deployments of CDC teams and also when the EOC is activated to respond to an international disease event.

The GDDOC monitors approximately 30 to 40 public health events each day and most closely watches those events that could develop into public health emergencies of international concern to which CDC may be asked to respond bilaterally by the country experiencing the outbreak, through the Global Outbreak Alert and Response Network (GOARN), or via both routes. Coordinated by the World Health Organization (WHO), GOARN is an independent collaboration of institutions and networks ready to respond to all-hazard threats of international importance. ${ }^{5}$ Typically, the GDDOC monitors outbreaks of infectious disease and, to a lesser extent, events involving other disease threats, including disasters, intoxications, and chemical, radiological, or nuclear events. The GDDOC also monitors outbreaks of unknown etiology, many of which are later determined to have an infectious cause; outbreaks among animals are also monitored for known zoonotic diseases and are continually assessed to determine whether human cases are associated with a particular outbreak. ${ }^{6}$ The GDDOC was created to alert CDC programs as soon as possible for the purpose of responding rapidly to mitigate the effects of an event, and, by conducting event-based surveillance, the GDDOC is able to better position CDC to respond earlier. Through rapid information gathering, prompt verification, and timely dissemination of information, the GDDOC ensures that CDC is always prepared to respond. CDC response teams can deploy internationally within 24 hours of learning about an outbreak.

During large-scale, international outbreaks or other public health events, the GDDOC may monitor up to 70 public health events, in different countries, attributable to a single etiology. For example, in November 2016 the GDDOC actively monitored 65 events, of which 29 were events describing autochthonously circulating Zika virus transmission in the Americas. ${ }^{7}$ When CDC's EOC is activated for such an event, the GDDOC also becomes part of the incident management system (IMS), a temporary, formal organization structure that supports a response, is flexible to meet rapidly changing demands of the response, and then disbands once the response is over. ${ }^{8}$ The GDDOC's specific role in the incident management system is to serve as part of an international task force (ITF), to facilitate the rapid sharing of outbreak-related information collected during event-based surveillance, which, when verified, assists in informing evidence-based decisions, including those directing how to best position CDC staff, funding, and other resources.

This report serves as an update to a previously published article, "What We Are Watching: Five Top Global Infectious Disease Threats, 2012: A Perspective from CDC's 
Global Disease Detection Operations Center," published in $2013 .{ }^{6}$ The 5 top potential threats of 2012 were based on subjective judgment, with input from CDC subject matter experts, regarding high transmissibility, disease burden, and severity; established or pandemic potential; disease eradication; and lack of available preventive or treatment interventions. The 5 potential top threats were not selected on the basis of an analytical algorithm or quantitative method. They were: avian influenza A (H5N1), cholera, poliomyelitis, enterovirus-71, and extensively drug-resistant tuberculosis, with addenda of MERS-Coronavirus and avian influenza A (H7N9), both of which were newly emerging. The same judgment was used to arrive at the top potential threats during 2013 to 2016, and the rationale for the selection of each is provided here. These threats have been attributed to recent or current outbreaks around the world, and future potential international outbreaks are not limited to those described in this article. Further, the GDDOC is continuously monitoring threats that could evolve into international outbreaks in the near future that would warrant placement in future updates to this report.

\section{Top Potential Infectious Disease Threats}

\section{Influenza Viruses}

Influenza viruses comprise 4 types: A, B, C, and D. Influenza $A$ viruses are further classified into subtypes on the basis of the characteristics of the 2 main surface glycoproteins, hemagglutinin (HA) and neuraminidase (NA), and numbered accordingly. While only 2 influenza $A$ virus subtypes (H3N2 and $\mathrm{H} 1 \mathrm{~N} 1 \mathrm{pdm} 09)$ are circulating among humans, the natural reservoir for nearly all influenza $\mathrm{A}$ viruses is wild waterfowl. Of the $18 \mathrm{HA}$ and $11 \mathrm{NA}$ influenza A virus subtypes, all but $\mathrm{H} 17 \mathrm{~N} 10$ and $\mathrm{H} 18 \mathrm{~N} 11$ viruses have been identified in birds. Some influenza A viruses circulate among pigs, and others have been identified in a wide number of animal species.

Only influenza A viruses cause seasonal influenza epidemics and rare pandemics among people. Influenza $\mathrm{B}$ viruses can cause seasonal epidemics, influenza $C$ viruses typically cause mild respiratory illness and do not cause epidemics, and influenza D viruses primarily affect cattle and are not known to cause illness in people.?

Novel influenza A viruses refer to viruses of animal origin that have infected humans and that are antigenically and genetically distinct from seasonal influenza A viruses circulating among people. We closely monitor novel influenza A viruses, because influenza A viruses continue to evolve and because zoonotic transmission could herald an increasing pandemic influenza health threat. If a novel influenza A virus acquires the ability for sustained human-tohuman transmission, a pandemic can result. Accordingly, early detection of pandemic-potential viruses may aid in the control and possible prevention of the next pandemic. Although a swine-origin influenza A virus caused the 2009 H1N1 pandemic, ${ }^{10,11}$ and sporadic transmission of swineorigin influenza A viruses to humans (termed "variant viruses") continue to be detected in the United States and in other countries with appropriate laboratory capacity, the public health threat posed by avian influenza A viruses appears to be higher because of their diversity and wide circulation among birds worldwide; the birds' migratory flyways may also be conducive to spread of influenza A viruses. Furthermore, some previous pandemic influenza A viruses have been partly of avian origin. ${ }^{11}$

\section{Avian Influenza A Viruses}

Avian influenza A viruses circulate widely among bird populations and can infect domestic poultry and other animal species, as well as causing sporadic human infections. Avian influenza A viruses are classified on the basis of molecular characteristics and pathogenicity criteria as "highly pathogenic" or "low pathogenic," which generally refers to the extent of disease in infected poultry. Highly pathogenic avian influenza $A$ virus infection of poultry can be rapidly fatal, whereas low-pathogenic avian influenza $A$ virus infection of poultry may be asymptomatic or cause only very mild disease. However, sporadic human infections with either low-pathogenic or highly pathogenic avian influenza A viruses can result in a wide spectrum of illness, ranging from mild to severe to fatal disease. The zoonotic disease potential is attributable to the close relationship humans share with birds: production (ie, as a food source) or companionship. Risk factors for human infection with avian influenza $A$ viruses include direct or close exposure to infected poultry, including backyard poultry, or working at or visiting a live poultry market. Although several novel influenza A viruses have been identified that are circulating among birds (eg, H5N1, H5N6, H6N1, H7N2, H7N3, H7N7, H7N9, H9N2, H10N7, H10N8), 2 subtypes of avian influenza $A$ viruses have caused the highest number of human infections and are of special concern.

\section{Highly Pathogenic Avian Influenza A (H5N1) Virus} Highly pathogenic avian influenza A (H5N1) virus infection of humans was first identified in 1997 in Hong Kong. The first case was identified in May of that year, and an additional 17 infections were detected in November and December 2017. ${ }^{12}$ Since then, H5N1 virus infections among humans have been reported in 16 countries, including 1 infection in a person who traveled to Beijing, China, and was diagnosed with pneumonia and meningoencephalitis after returning to Canada in late $2013 .{ }^{13} \mathrm{Be}$ tween November 2003 and April 2017, a total of 858 infections with 453 deaths in humans attributable to highly pathogenic avian influenza A (H5N1) virus infection were reported to WHO. ${ }^{14}$ Of the 858 infections, 793 (92.4\%) 
have been reported from 5 countries: Egypt (358 infections), Indonesia (199), Vietnam (127), Cambodia (56), and China (53). ${ }^{14}$ Of all reported infections, 52.8\% (453/ 858) have been fatal. ${ }^{15} \mathrm{H} 5 \mathrm{~N} 1$ virus infection can cause rapidly progressive pneumonia and multiple organ failure, leading to death. ${ }^{16}$ Risk factors include direct or close exposure to sick or dead infected poultry or visiting a live poultry market. ${ }^{17,18}$ Highly pathogenic avian influenza A $(\mathrm{H} 5 \mathrm{~N} 1)$ virus is of major concern because case clusters representing limited, nonsustained human-to-human transmission has been reported in multiple countries, ${ }^{19-21}$ and viral evolution is ongoing in infected poultry.

\section{Low-Pathogenic Avian Influenza A (H7N9) Virus}

The first 3 human infections with low-pathogenic avian influenza A (H7N9) virus were reported in China in March 2013 from Shanghai Special Administrative Region (2 infections) and Anhui Province (1), and all were fatal. ${ }^{22,23}$ This was the first time that infection with a low-pathogenic avian influenza A virus had caused severe and fatal human disease. Since then, infections in humans with low-pathogenic avian influenza A (H7N9) virus infection have been reported from throughout China. ${ }^{24}$

As of April 2017, there were nearly 1,400 infections in humans with avian influenza A (H7N9), with at least 530 deaths reported to $\mathrm{WHO},{ }^{25}$ including those reported from China's Special Administrative Region (SAR) of Hong Kong (21 infections). Of particular concern are those that were acquired in China and then subsequently exported to other countries and later diagnosed, allowing potential autochthonous transmission in those areas, including Taiwan SAR (5), Canada (2), Macao SAR (2), and Malaysia (1). ${ }^{25}$ Most reported infections with avian influenza A (H7N9) have been hospitalized with pneumonia, and decedents had multi-organ failure. ${ }^{26}$

Risk factors for H7N9 virus infection are visiting or working at a live poultry market and raising backyard poultry in China. ${ }^{27,28}$ Prevention measures have included the temporary closure and decontamination of live poultry markets. ${ }^{29,30}$ While studies have shown that the exposure potential of avian influenza A (H7N9) virus persists in live poultry markets, closure and decontamination of these markets may rapidly reduce the occurrence of infections of avian influenza $A(H 7 N 9)$ virus in poultry, thus preventing transmission of the virus to humans. ${ }^{31}$

During the fifth epidemic of this outbreak, which began October 1, 2016, there was a significant increase in human infections with avian influenza A (H7N9) compared with the first 4 epidemics. ${ }^{32,33}$ The number of provinces with $\mathrm{H} 7 \mathrm{~N} 9$ infections has increased, and some human infections with highly pathogenic avian influenza A (H7N9) virus have been reported in 2017, suggesting ongoing evolution of $\mathrm{H} 7 \mathrm{~N} 9$ viruses in poultry. ${ }^{34} \mathrm{We}$ are constantly monitoring disease reports that not only report human illness, but that also report detection of H7N9 virus in poultry, including backyard poultry and in live poultry markets.

\section{Cholera}

Cholera remains a top potential threat that we continuously monitor very closely. ${ }^{6}$ Cholera is an acute gastrointestinal infection caused by ingestion of food or water containing the bacterium Vibrio cholerae serogroup $\mathrm{O} 1$ or $0139 .{ }^{35} \mathrm{~V}$. cholerae continues to infect, and kill, large numbers of people very quickly; it spreads easily through crowded environments with fractured water and sanitation infrastructure, such as densely populated urban slums and settlements for internally displaced persons. In 2015, 42 countries reported to WHO a total of 172,454 cases with 1,304 deaths attributable to cholera, although an estimated 2.8 million cases and 91,000 deaths are thought to occur each year. ${ }^{36,37}$ Of the 172,454 reported cases, 71,176 cases (41.3\%) and 937 deaths (74.6\%) were reported from subSaharan Africa; ${ }^{38}$ none of these cases was imported.

Notably, cases were reported from Democratic Republic of Congo (DRC) (19,182 cases), Kenya (13,291), Tanzania $(11,563)$, Mozambique $(8,739)$, Somalia $(7,536)$, and Nigeria (5,290). These 6 countries together reported 821 deaths, resulting in a case-fatality proportion of $1.25 \%$; no cases were reported from northern Africa. ${ }^{38}$ Cholera continues to be a threat in sub-Saharan Africa, the region with the lowest coverage of improved water and sanitation and a multitude of health system challenges. Epidemic cholera creates an additional burden on health facilities and personnel already stressed by HIV/AIDS, malaria, tuberculosis, and other infectious and noninfectious causes of morbidity and mortality (eg, malnutrition).

Asia reported 64,590 cases with 30 deaths to WHO in 2015, with most cases reported from Afghanistan (58,064; $89.9 \%$ ) and Iraq (4,965; 7.7\%); of the 64,590 cases, 57 were reported to be imported cases, into Iran (36), Bahrain (8), Japan (7), Kuwait (5), and Oman (1). ${ }^{38}$

Of increasing concern over the past several years is the establishment of cholera in the Americas, beginning with Haiti, which first reported cases in association with an outbreak in October 2010 that ultimately resulted in 754,972 cases and 8,863 deaths through the end of 2015. A total of 36,045 cases were reported in 2015 alone, which represents an increase of $30 \%$ in case counts from 2014. Despite the continued efforts of the Minstère de la Santé Publique et de la Population, cholera has maintained a presence in the country since the 2010 outbreak. And like sub-Saharan Africa, with a less than ideal healthcare infrastructure, the well-proven risk of explosive epidemics in Haiti and of spread to other nations remains as long as cholera is present. $^{39}$

To combat endemic and epidemic cholera, in 2013 WHO created the world's first oral cholera vaccine (OCV) stockpile, which continues to expand. ${ }^{40}$ Since operations began, a total of 21 oral cholera vaccine deployments of about 4 million doses to 11 countries have been used in various contexts: humanitarian crises in Cameroon, Haiti, Iraq, Nepal, South Sudan, and the United Republic of 
Tanzania; outbreaks in Guinea and Malawi; and in endemic areas such as Bangladesh and DRC. ${ }^{41}$ Also of note, to prevent international spread of cholera, particularly among travelers, is the recent licensure and availability of Vaxchora $^{\mathrm{TM}}$, a single-dose, live attenuated, oral cholera vaccine in the United States, the first cholera vaccine to be licensed in the United States in many decades and the only one that is available in the United States. ${ }^{42}$

In 2016, GDDOC closely watched and reported on widespread and persistent epidemics of cholera in Haiti, Kenya, Tanzania, DRC, South Sudan, the Central African Republic, Burundi, Benin, Ethiopia (acute watery diarrhea), Djibouti, and Yemen and have responded to requests for assistance or otherwise provided technical assistance to Haiti, Kenya, Tanzania, and DRC. We will continue to monitor reports of cholera, particularly those reports that could signify exportation into a country with an alreadyweakened healthcare system, placing the country at risk for Vibrio cholerae to become established, as occurred in Haiti.

\section{Ebola Virus Disease}

Ebola virus disease (EVD) was first discovered in 1976 when an outbreak of an acute viral hemorrhagic fever occurred in what was formerly northern Zaire, with secondary and tertiary cases reported in the city of Kinshasa. Signs and symptoms were nonspecific at clinical onset but progressed to include others such as sore throat, fever, maculopapular rash, abdominal pain, and bleeding. ${ }^{43}$ Ultimately, there were 318 cases reported in association with this outbreak, with 280 deaths. Laboratory investigations revealed the outbreak was caused by a virus similar to Marburg virus (discovered in 1969), and it was named Ebola virus. Ebola virus is now a member of the genus Ebolavirus (in the Filoviridae family), which contains 5 related virus species: Ebola, Sudan, Reston, Tai Forest, and Bundibugyo ebolaviruses. Since their discovery, these viruses have been the cause of more than 30 separate reported outbreaks. ${ }^{44}$ Fatality rates vary between the viruses and among outbreaks, however; for example, Reston ebolavirus infection does not cause disease in humans, only in nonhuman primates. ${ }^{45,46}$

Outbreaks of EVD had been limited to localized outbreaks in sub-Saharan Africa or laboratory exposures until March 2014, when approximately 50 cases (with 10 deaths) of an unspecified viral hemorrhagic fever were reported in the forested southeastern prefectures of Macenta and Gueckedou, Guinea, close to the border with Sierra Leone. Signs and symptoms associated with these cases included high fever, diarrhea, vomiting, and bleeding. Specimens tested at Institut Pasteur's BSL-4 facility in Lyon, France, indicated that these cases were attributable to a filovirus, one of a family of single-stranded negative-sense RNA viruses that can cause severe hemorrhagic fever in humans and nonhuman primates. ${ }^{47}$ On March 22, the outbreak was confirmed as an Ebola virus (Zaire ebolavirus) associated outbreak. Cases had increased to a total of 86 cases with 59 deaths; all cases were epidemiologically linked and included healthcare workers. ${ }^{48}$ Later that March, cases began to be reported from other Guinean prefectures, including the capital Conakry, and from Liberia in patients who had traveled to Guinea prior to illness onset; additional cases began to be reported from Sierra Leone and Nigeria.

In July and August 2014, based on widespread transmission and crossing of international borders, CDC's EOC was activated to provide an agency-wide response to the outbreak, and WHO declared the outbreak a public health event of international concern (PHEIC), defined as an extraordinary event determined to constitute a public health risk to other states parties through the international spread of disease and to potentially require a coordinated international response. ${ }^{49}$ National and international partners put in place a multitude of actions to mitigate the enlarging outbreak, including activation of national disaster and emergency management mechanisms, support of clinical and diagnostic facilities, and coordination across communities, including medical facilities, as well as anthropological support to involve the general population, traditional healers, and religious entities. ${ }^{50}$

Ultimately, this outbreak in West Africa grew to be the largest EVD outbreak ever recorded. As of March 2016, a total of 28,646 suspected, probable, and laboratoryconfirmed cases with 11,323 deaths had been reported from Guinea (3,811 cases; 2,543 deaths), Liberia (10,675; 4,809), Sierra Leone $(14,124 ; 3,956)$, Nigeria $(20 ; 8)$, Mali $(8 ; 6)$, and Senegal (1 case), resulting from importation of cases and minimal sustained transmission. The remainder of cases were a result of importation or travel: Italy (1 case), Spain (1), the United Kingdom (1), and the United States (4 cases; 1 death). ${ }^{51}$

We monitored this global outbreak very closely because of the unforeseen explosion of cases and transmission across international borders. This occurred as a result of weakened or fractured healthcare infrastructure, continued infection of healthcare workers, and anthropologic or cultural concerns, such as families hiding their deceased family members-all contributing to propagation of the outbreak. The outbreak was declared over in June 2016; however, we continue to closely monitor any reports, including media reports, from West Africa in hopes of quickly identifying any additional EVD that could be a result of, for example, sexual transmission from EVD survivors. ${ }^{52,53}$ (Recent studies have indicated that Ebola virus can survive in semen for extended periods of time. ${ }^{54,55}$ ) Not limiting ourselves to Ebola virus, we closely monitor any reports of cases that could appear to be a viral hemorrhagic fever, so we may provide early warning for a rapid response to prevent another massive global outbreak.

\section{Vector-Borne Diseases}

Three vector-borne viruses have caused large outbreaks of disease since 2013: yellow fever, chikungunya, and Zika viruses. While yellow fever virus caused a relatively discrete 
outbreak originating in Angola with exported cases and has been declared over, chikungunya and Zika virus continue to spread across the Americas. The GDDOC intensely monitors vector-borne diseases for their ability to spread quickly via a competent arthropod vector, most notably Aedes aegypti and Aedes albopictus. Further, the GDDOC was and continues to be part of CDC's response to the Zika virus outbreak, serving on the EOC's international task force. While the EOC was not activated for the recent yellow fever outbreak or the continuing spread of chikungunya virus, the GDDOC focused event-based surveillance on these 2 pathogens and also assisted in the deployment of staff to sub-Saharan Africa for the yellow fever outbreak.

\section{Yellow Fever}

Yellow fever warrants a place on our list of top potential threats to monitor because of the explosive outbreak that began in late 2015 in Angola. The outbreak spread to all provinces in the country and to adjacent DRC in $2016 .^{56}$ The first travel-related cases of yellow fever disease since 2002 were identified in association with this outbreak, with travel-associated cases exported to China (11 cases), Kenya ( 2 cases), and Mauritania (1 case). ${ }^{57,58}$

Yellow fever can present as an acute viral hemorrhagic disease and is fatal in $20 \%$ to $50 \%$ of severe cases. It is caused by yellow fever virus, the prototypic virus in the genus Flavivirus. The virus is transmitted through the bite of a mosquito and is endemic to sub-Saharan Africa and tropical areas of South America. ${ }^{59}$ Large epidemics of yellow fever occur when infected people introduce the virus into heavily populated areas with $A e$. aegypti, the urban vector, leading to autochthonous transmission of the virus that can quickly lead to outbreaks of great magnitude.

The Angolan Public Health Institute first notified WHO of 4 cases of a febrile jaundice syndrome with bleeding on December 30, 2015. Of these patients, 3 had already died, and the other died on December 31, 2015. All cases were young men residing in Luanda, Angola, and several of them reportedly had proof of vaccination against yellow fever (eg, in possession of a yellow card). Laboratory testing conducted at the National Institute for Communicable Diseases of the National Health Laboratory Service, Johannesburg, South Africa, consisted of testing for filoviruses, arenaviruses, and bunyaviruses, as well as for chikungunya and dengue viruses, by using reverse transcription PCR (RT-PCR); all tests were negative. ${ }^{59}$ However, a realtime RT-PCR for yellow fever virus produced positive results for samples from 3 of the patients. The results were reported back to the Angolan Public Health Institute on January 19, 2016, and a subsequent investigation determined that the cases had not been vaccinated against yellow fever; they had falsified yellow cards. ${ }^{60}$

Since that time, a total of 4,347 suspected cases with 377 deaths have been reported to WHO; of these, 884 cases and 121 deaths were laboratory confirmed. ${ }^{61}$ Since the start of the outbreak, laboratory-confirmed cases have been reported from 80 districts in 16 of 18 provinces. Autochthonous transmission was reported in 45 districts in 12 provinces. ${ }^{61}$ The last confirmed case had symptom onset on June 23, 2016.

In early 2016, the DRC reported many cases of yellow fever disease in travelers going to and from Angola. By May 2016, the first autochthonous case associated with the outbreak in Angola was recognized in the country, with subsequent local cases identified in several additional provinces in the west of the country, including the capital of Kinshasa. A total of 2,987 suspected cases were reported from all 26 provinces, with 78 cases from 8 provinces having laboratory confirmation. The last confirmed case had symptom onset on July 12, 2016.

Additional suspected cases continue to occur, but none have been confirmed by laboratory testing. The response to this outbreak continues in both countries, including ongoing vaccination campaigns: by October 25, 2016, approximately 20 million doses of yellow fever vaccine have been distributed in reactive, preemptive, and preventive emergency vaccination campaigns in Angola and 9.4 million have been distributed in the DRC. ${ }^{61}$ The large demand for vaccine created by these outbreaks led to an unprecedented shortage of vaccine and to the approval by the Strategic Advisory Group of Experts on Immunization at WHO to use fractional doses of the vaccine, which was done in Kinshasa to preempt further spread.

In May 2016, WHO held a meeting of the emergency committee under the International Health Regulations (2005) concerning yellow fever. Although the committee did not declare yellow fever a public health emergency of international concern, they did note that the urban yellow fever outbreaks in Angola and the DRC were a serious public health event warranting intensified national action and enhanced international support. ${ }^{62}$ With an abundant competent mosquito vector, large susceptible populations, and limitations of vaccine supply, yellow fever can potentially spread quickly throughout a population, including to those outside of traditional areas known to be endemic, thereby warranting sustained, focused surveillance by the GDDOC.

\section{Chikungunya}

Prior to 2013, chikungunya virus had not been reported in the Americas. On December 6, 2013, colleagues at the European Centre for Disease Prevention and Control informed the GDDOC of laboratory-confirmed autochthonous cases of chikungunya being reported on St. Martin, a Caribbean island and overseas collectivity of France. ${ }^{63}$ Chikungunya virus is an alphavirus spread by Aedes stegomyia mosquitoes, with humans serving as the primary reservoir during epidemics. The virus can cause fast-moving, expansive outbreaks-for example, during 2005-06, an estimated $40 \%$ of the population of La Réunion was infected with chikungunya virus; ${ }^{64}$ in 2006 , an estimated 1.38 million people in India were infected; ${ }^{65}$ and during 
2008-09, Thailand reported more than 49,000 cases of chikungunya in 50 provinces of that country. ${ }^{66}$ During the first year of the outbreak in the Americas, the disease spread to 43 countries or territories, with more than 1.1 million suspected cases reported to the Pan American Health Organization (PAHO) from affected areas. As of early November 2016, there have been an additional 1.2 million suspected autochthonous transmission cases reported to PAHO from January 2015 to November 2016. ${ }^{67}$

Chikungunya virus causes fever, rash, and most notably severe arthralgia; it is rarely fatal, but the arthralgia can be severely debilitating and, in some people, initiate a lifetime of chronic pain and disability. ${ }^{68}$ There is neither a specific treatment for chikungunya nor a vaccine to prevent it; care is typically supportive. ${ }^{67}$ The GDDOC continues to conduct event-based surveillance for reports of illness potentially attributable to chikungunya virus and informs leaders of findings. Further, streamlined communications with CDC's Division of Vector-Borne Diseases as well as with PAHO allow for prioritization of resources, including staff and funding.

\section{Zika Virus}

Zika virus was identified in 1947 when it was discovered in a sentinel rhesus monkey during routine surveillance for yellow fever in the Zika Forest near Entebbe, Uganda. The first human cases were identified in 1952 in Uganda and Tanzania, ${ }^{69}$ with few reports of human infection in Asia and Africa over the next several decades. ${ }^{70}$ However, in 2007 on Yap Island, Micronesia, an outbreak of an unknown illness among patients with signs and symptoms including rash, conjunctivitis, and arthralgia was identified to be attributable to Zika virus; the outbreak resulted in 49 laboratory confirmed and 59 probable cases of Zika virus and led to more than $70 \%$ of the population being infected with the virus. ${ }^{71}$ Starting in 2013, outbreaks throughout the Pacific islands were attributed to Zika virus, resulting in thousands of suspected and probable infections as well as an increase in the incidence of Guillain-Barré syndrome (GBS). ${ }^{63}$ In March 2015, Brazil notified WHO of an unknown illness among humans with rash, occurring in northeastern states; tests for chikungunya, measles, rubella, parvovirus B19, and enterovirus were negative. ${ }^{69}$ It was not until the following month that Bahia State Laboratory tested samples that yielded positive results for Zika virus, and in May Brazil's national reference laboratory confirmed Zika virus in a patient's blood by RT-PCR, confirming nationwide circulation of the virus. ${ }^{69}$ Since that time, Zika virus has spread across the Americas, and as of September 2016, nearly 50 countries and territories in the Americas have reported autochthonous, vector-borne transmission of the virus. A total of 73 countries and territories worldwide have reported evidence of mosquito-borne Zika virus transmission since 2007 , with 71 of those reports since 2015 . $^{72}$

Zika virus is in the genus Flavivirus and, like dengue and chikungunya, is transmitted primarily by Aedes stegomyia species mosquitoes, notably Ae. aegypti and Ae. albopictus. Both mosquito species are present in the United States, with Ae. albopictus having a much wider range. ${ }^{73}$ However, unlike chikungunya or dengue viruses, Zika virus has been documented to be spread through sexual transmission, complicating the transmission dynamics of this virus. Zika virus infections are often asymptomatic or produce a mild rash illness among healthy adults and children infected after birth. However, in addition to its association with GBS, Zika virus infections in pregnancy now have been associated with congenital infection typically resulting in microcephaly and other nervous system defects. ${ }^{74}$ It is the association with the neurologic diseases, both microcephaly and GBS, that prompted WHO to declare the neurologic diseases and their potential association with Zika virus a public health event of international concern, ${ }^{75}$ and which has caused Zika virus to be one of the GDDOC's top potential global threats that we are monitoring.

With the uncontrolled transmission of the virus by wide-ranging Aedes mosquitoes and limited ability to control these populations, the threat of an increasingly large epidemic of microcephaly throughout the Americas and other regions is very real. The effect of microcephaly on newborns is devastating, potentially resulting in lifelong developmental challenges for these infants, ${ }^{74}$ which will create not only healthcare and emotional challenges for families, but also place an inordinate burden on healthcare systems and public health infrastructure attempting to provide long-term care for these children. We will continue to monitor Zika virus epidemiology and relay additional information about its spread, pathogenesis, and clinical outcomes as our knowledge about this virus continues to evolve.

\section{Updates}

\section{Middle East Respiratory Syndrome-Coronavirus (MERS-CoV)}

As of mid-December 2016, a total of 1,864 cases of MERS$\mathrm{CoV}$ with at least 659 deaths had been reported to WHO from the Middle Eastern and northern African countries of Saudi Arabia, United Arab Emirates (UAE), Qatar, Jordan, Oman, Iran, Tunisia, Kuwait, Algeria, Yemen, and Lebanon; exported cases were also reported in the United Kingdom, France, the Netherlands, Italy, Turkey, Germany, the Philippines, and the Republic of Korea. ${ }^{76}$ Of note in the Republic of Korea, an exported case of MERS$\mathrm{CoV}$ in an emergency department patient with a history of travel to Bahrain, UAE, Saudi Arabia, and Qatar resulted in an outbreak of 186 cases of MERS-CoV with 36 deaths. Although the index exposure occurred in a large, crowded emergency facility, the affected hospital and the health ministry were quickly able to mitigate the outbreak. ${ }^{77}$ This event in South Korea demonstrates how quickly MERS$\mathrm{CoV}$ can be transmitted from person to person in a tertiary 
care hospital in a developed health infrastructure, further underscoring the necessity to monitor cases of MERS-CoV.

\section{Poliomyelitis}

By the end of 2012, 223 confirmed cases of wild poliomyelitis (WPV) were reported from countries with endemically circulating wild poliovirus: Afghanistan (37), Pakistan (58), and Nigeria (122), and 5 cases were reported from Chad. Since then, cases of wild poliomyelitis have declined, after a peak in 2013 (416 cases), trending downward through 2014 (359 cases), 2015 (74 cases), and, as of April 19, 2017, 5 cases of wild poliomyelitis had been reported to $\mathrm{WHO}$, compared with 11 cases at the same time in 2016. As of April 19, 2017, no cases of circulating vaccine-derived poliovirus (cVDPV) had been reported to WHO compared with 3 cases at the same time in $2016 .^{78}$ Nigeria, which had been polio-free during 2015 and was removed from WHO's polio-endemic list in September of that year, ${ }^{79}$ unfortunately reported cases during 2016, placing it back on the endemic list. ${ }^{80}$ Monitoring polio will continue to be important because of the debilitating neurologic disease poliovirus causes, but it will also be paramount in the post-eradication era, as even 1 case will represent an international public health emergency.

\section{Summary}

This report describes top potential global infectious disease threats that the GDDOC was monitoring during 2013-2016, and does not necessarily describe those public health events that CDC finds most important or events that require the most resources. With the unique platform from which event-based surveillance is conducted, the GDDOC is in a unique position to rapidly identify new threats to public health, including those that could lead to a pandemic.

\section{REFERENCES}

1. World Health Organization. Early Detection, Assessment, and Response to Acute Public Health Events: Implementation of Early Warning and Response with a Focus on Event-Based Surveillance. Interim Version. 2014. http://apps.who.int/iris/ bitstream/10665/112667/1/WHO_HSE_GCR_LYO_2014.4_ eng.pdf?ua=1. Accessed July 27, 2017.

2. Centers for Disease Control and Prevention. The Global Health Security Agenda. CDC website. Updated January 27, 2016. https://www.cdc.gov/globalhealth/security/ghsagenda. htm. Accessed July 28, 2017.

3. Executive Office of the President; National Science and Technology Council. National Biosurveillance Science and Technology Roadmap. June 2013. https://obamawhitehouse. archives.gov/sites/default/files/microsites/ostp/biosurveillance_ roadmap_2013.pdf. Accessed July 28, 2017.
4. Department of Defense. Global Emerging Infections Surveillance and Response System. Health.mil website. 2017. https://www.health.mil/Military-Health-Topics/HealthReadiness/Armed-Forces-Health-Surveillance-Branch/GlobalEmerging-Infections-Surveillance-and-Response. Accessed July 28, 2017.

5. World Health Organization. International Health Regulations (2005): Global Outbreak Alert and Response Network (GOARN). WHO website. May 2015. http://www.who. int/ihr/about/IHR_Global_Outbreak_Alert_and_Response_ Network_respond.pdf?ua=1. Accessed September 30, 2016.

6. Christian KA, Ijaz K, Dowell SF, et al. What we are watching-five top global infectious disease threats, 2012: a perspective from CDC's Global Disease Detection Operations Center. Emerg Health Threats J 2013;6:20632.

7. Global Disease Detection Operations Center. Event Analysis Management System. 2016. Centers for Disease Control and Prevention. https://www.cdc.gov/globalhealth/healthprotection/ gddopscenter/index.html. Accessed July 28, 2017.

8. Centers for Disease Control and Prevention. CDC Emergency Operations Center: how an EOC works. CDC website. Updated August 25, 2016. https://www.cdc.gov/phpr/ eoc/building-an-eoc.htm. Accessed July 28, 2017.

9. Centers for Disease Control and Prevention. Types of influenza viruses. CDC website. Updated September 15, 2016. https://www.cdc.gov/flu/about/viruses/types.htm. Accessed July 28, 2017.

10. Garten RJ, Davis CT, Russell CA, et al. Antigenic and genetic characteristics of swine-origin 2009 A(H1N1) influenza viruses circulating in humans. Science 2009;325(5937):197-201.

11. Neumann G, Noda T, Kawaoka Y. Emergence and pandemic potential of swine-origin $\mathrm{H} 1 \mathrm{~N} 1$ influenza virus. Nature 2009;459(7249):931-939.

12. Chan PK. Outbreak of avian influenza $\mathrm{A}(\mathrm{H} 5 \mathrm{~N} 1)$ virus infection in Hong Kong in 1997. Clin Infect Dis 2002; 34(Suppl 2):S58-S64.

13. Rajabali N, Lim T, Sokolowski C, Prevost JD, Lee EZ. Avian influenza A ( $\mathrm{H} 5 \mathrm{~N} 1)$ infection with respiratory failure and meningoencephalitis in a Canadian traveller. Can J Infect Dis Med Microbiol 2015;26(4):221-223.

14. World Health Organization. Cumulative number of confirmed human cases for avian influenza $\mathrm{A}(\mathrm{H} 5 \mathrm{~N} 1)$ reported to WHO, 2003-2017. http://www.who.int/influenza/human_ animal_interface/2017_04_20_tableH5N1.pdf?ua=1. Accessed July 31, 2017.

15. Lai S, Qin Y, Cowling BJ, et al. Global epidemiology of avian influenza A H5N1 virus infection in humans, 19972015: a systematic review of individual case data. Lancet Infect Dis 2016;16(7):e108-118.

16. Writing Committee of the Second World Health Organization Consultation on Clinical Aspects of Human Infection with Avian Influenza A (H5N1) Virus, Abdel-Ghafar AN, Chotpitayasunondh T, Gao Z, et al. Update on avian influenza A (H5N1) virus infection in humans. $N$ Engl J Med 2008;358(3):261-273.

17. Zhou L, Liao Q, Dong L, et al. Risk factors for human illness with avian influenza A (H5N1) virus infection in China. J Infect Dis 2009;199(12):1726-1734.

18. Dinh PN, Long HT, Tien NT, et al.; World Health Organization/Global Outbreak Alert and Response Network Avian Influenza Investigation Team in Vietnam. Risk factors 
for human infection with avian influenza A H5N1, Vietnam, 2004. Emerg Infect Dis 2006;12(12):1841-1847.

19. Ungchusak K, Auewarakul P, Dowell SF, et al. Probable person-to-person transmission of avian influenza A (H5N1). $N$ Engl J Med 2005;352(4):333-340.

20. Wang H, Feng Z, Shu Y, et al. Probable limited person-toperson transmission of highly pathogenic avian influenza $\mathrm{A}$ (H5N1) virus in China. Lancet 2008;371(9622):1427-1434.

21. Kandun IN, Wibisono H, Sedyaningsih ER, et al. Three Indonesian clusters of $\mathrm{H} 5 \mathrm{~N} 1$ virus infection in 2005. N Engl $J$ Med 2006;355(21):2186-2194.

22. Gao R, Cao B, Hu Y, et al. Human infection with a novel avian-origin influenza A (H7N9) virus. $N$ Engl J Med 2013; 368(20):1888-1897.

23. Uyeki TM, Cox NJ. Global concerns regarding novel influenza A (H7N9) virus infections. N Engl J Med 2013; 368(20):1862-1864.

24. Li Q, Zhou L, Zhou M, et al. Epidemiology of human infections with avian influenza $\mathrm{A}(\mathrm{H} 7 \mathrm{~N} 9)$ virus in China. $N$ Engl J Med 2014;370(6):520-532.

25. World Health Organization. Human infection with avian influenza $\mathrm{A}(\mathrm{H} 7 \mathrm{~N} 9)$ virus - China. WHO website. April 20, 2017. http://www.who.int/csr/don/20-april-2017-ah7n9china/en/. Accessed July 31, 2017.

26. Gao HN, Lu HZ, Cao B, et al. Clinical findings in 111 cases of influenza A (H7N9) virus infection. N Engl J Med 2013; 368(24):2277-2285.

27. Liu B, Havers F, Chen E, et al. Risk factors for influenza $\mathrm{A}(\mathrm{H} 7 \mathrm{~N} 9)$ disease-China, 2013. Clin Infect Dis 2014;59(6): 787-794.

28. Zhou L, Ren R, Ou J, et al. Risk factors for influenza $\mathrm{A}(\mathrm{H} 7 \mathrm{~N} 9)$ disease in China, a matched case control study, October 2014 to April 2015. Open Forum Infect Dis 2016; 3(3): ofw182.

29. Yu H, Wu JT, Cowling BJ, et al. Effect of closure of live poultry markets on poultry-to-person transmission of avian influenza A H7N9 virus: an ecological study. Lancet 2014; 383(9916):541-548.

30. Peiris JS, Cowling BJ, Wu JT, et al. Interventions to reduce zoonotic and pandemic risks from avian influenza in Asia. Lancet Infect Dis 2016;16(2):252-258.

31. Yuan J, Lau EH, Li K, et al., Effect of live poultry market closure on avian influenza $\mathrm{A}(\mathrm{H} 7 \mathrm{~N} 9)$ virus activity in Guangzhou, China, 2014. Emerg Infect Dis 2015;21(10): 1784-1793.

32. Iuliano $\mathrm{AD}$, Jang $\mathrm{Y}$, Jones $\mathrm{J}$, et al. Increase in human infections with avian influenza $\mathrm{A}(\mathrm{H} 7 \mathrm{~N} 9)$ virus during the fifth epidemic-China, October 2016-February 2017. MMWR Morb Mortal Wkly Rep 2017;66(9):254-255.

33. Zhou L, Ren R, Yang L, et al. Sudden increase in human infection with avian influenza $\mathrm{A}(\mathrm{H} 7 \mathrm{~N} 9)$ virus in China, September-December 2016. Western Pac Surveill Response J 2017;8:6-14.

34. World Health Organization. Human infection with avian influenza $\mathrm{A}(\mathrm{H} 7 \mathrm{~N} 9)$ virus - China. WHO website. February 27, 2017. http://www.who.int/csr/don/27-february-2017ah7n9-china/en/. Accessed July 31, 2017.

35. World Health Organization. Cholera. WHO website. Updated July 2017. http://www.who.int/mediacentre/factsheets/ fs107/en/. Accessed July 31, 2017.
36. Ali M, Lopez AL, You YA, et al., The global burden of cholera. Bull World Health Organ 2012;90(3):209-218A.

37. World Health Organization. Global Health Observatory (GHO) data. Number of reported cholera cases. WHO website. 2016. http://www.who.int/gho/epidemic_diseases/ cholera/cases_text/en/. Accessed July 31, 2017.

38. World Health Organization. Cholera, 2015. Wkly Epidemiol $\operatorname{Rec} 2016 ; 91(38): 433-440$.

39. Ivers LC. Eliminating cholera transmission in Haiti. $N$ Engl J Med 2017;376(2):101-103.

40. World Health Organization. Cholera vaccine supply set to double, easing global shortage. WHO website. January 8 , 2016. http://www.who.int/cholera/vaccines/double/en/. Accessed July 31, 2017.

41. World Health Organization. WHO and partners protect more than 1 million people from cholera. WHO website. April 11, 2016. http://www.who.int/cholera/news/who-protectfrom-cholera/en/. Accessed July 31, 2017.

42. U.S. Food and Drug Administration. FDA approves vaccine to prevent cholera for travelers [press release]. FDA website. June 10, 2016. http://www.fda.gov/NewsEvents/Newsroom/ PressAnnouncements/ucm 506305.htm. Accessed July 31, 2017.

43. World Health Organization. Ebola haemorrhagic fever in Zaire, 1976. Bull World Health Organ 1978;56(2):271-293.

44. Centers for Disease Control and Prevention. Outbreaks chronology: Ebola virus disease. CDC website. Updated July 24, 2017. https://www.cdc.gov/vhf/ebola/outbreaks/history/ chronology.html. Accessed July 31, 2017.

45. World Health Organization. Ebola virus disease. WHO website. Updated June 2017. http://www.who.int/mediacentre/ factsheets/fs103/en/. Accessed July 31, 2017.

46. Rollin PE, Williams RJ, Bressler DS, et al. Ebola (subtype Reston) virus among quarantined nonhuman primates recently imported from the Philippines to the United States. J Infect Dis 1999;179(Suppl 1):S108-S114.

47. Centers for Disease Control and Prevention. Viral hemorrhagic fevers (VHFs): Filoviridae. CDC website. Updated April 7, 2014. https://www.cdc.gov/vhf/virus-families/filoviridae. html. Accessed July 31, 2017.

48. World Health Organization. Ebola Hemorrhagic Fever in Guinea. WHO website. 2016. http://www.afro.who.int/en/ clusters-a-programmes/dpc/epidemic-a-pandemic-alert-andresponse/outbreak-news/4063-ebola-hemorrhagic-fever-inguinea.html.

49. World Health Organization. International Health Regulations (2005). 3rd ed. http://www.who.int/ihr/publications/ 9789241580496/en/. Accessed July 31, 2017.

50. World Health Organization. Statement on the 1 st meeting of the IHR Emergency Committee on the 2014 Ebola outbreak in West Africa. August 8, 2014. http://www.who.int/ mediacentre/news/statements/2014/ebola-20140808/en/. Accessed July 28, 2017.

51. World Health Organization. Ebola situation reports. WHO website. 2016. http://apps.who.int/ebola/ebola-situation-reports. Accessed July 31, 2017.

52. Diallo B, Sissoko D, Loman NJ, et al. Resurgence of Ebola virus disease in Guinea linked to a survivor with virus persistence in seminal fluid for more than 500 days. Clin Infect Dis 2016;63(10):1353-1356. 
53. Mate SE, Kugelman JR, Nyenswah TG, et al. Molecular evidence of sexual transmission of Ebola virus. $N$ Engl J Med 2015;373(25):2448-2454.

54. Soka MJ, Choi MJ, Baller A, et al. Prevention of sexual transmission of Ebola in Liberia through a national semen testing and counselling programme for survivors: an analysis of Ebola virus RNA results and behavioural data. Lancet Glob Health 2016;4(10):e736-743.

55. Uyeki TM, Erickson BR, Brown S, et al. Ebola virus persistence in semen of male survivors. Clin Infect Dis 2016 62(12):1552-1555.

56. World Health Organization. Situation report: yellow fever. WHO website. June 30, 2016. http://www.who.int/ emergencies/yellow-fever/situation-reports/30-june-2016/en/. Accessed July 31, 2017.

57. World Health Organization. Yellow fever - Angola. WHO website. June 14, 2016. http://www.who.int/csr/don/14june-2016-yellow-fever-angola/en/. Accessed July 31, 2017.

58. European Centre for Disease Prevention and Control. Outbreak of yellow fever in Angola - 24 March 2016. http:// ecdc.europa.eu/en/publications/publications/yellow-fever-riskassessment-angola-china.pdf.

59. World Health Organization. Yellow fever. Fact sheet. WHO website. Updated May 2016. http://www.who.int/mediacentre/ factsheets/fs100/en/. Accessed July 31, 2017.

60. Grobbelaar AA, Weyer J, Moolla N, Jansen van Vuren P, Moises F, Paweska JT. Resurgence of yellow fever in Angola, 2015-2016. Emerg Infect Dis 2016;22(10):1854-1855.

61. World Health Organization. Situation report: yellow fever. WHO website. October 28, 2016. http://apps.who.int/iris/ bitstream/10665/250661/1/yellowfeversitrep28Oct16-eng.pdf? ua $=1$. Accessed July 31, 2017.

62. World Health Organization. Meeting of the emergency committee under the International Health Regulations (2005) concerning yellow fever. May 19, 2016. http://www. who.int/mediacentre/news/statements/2016/ec-yellow-fever/ en/. Accessed July 31, 2017.

63. Oehler E, Watrin L, Larre $P$, et al. Zika virus infection complicated by Guillain-Barre syndrome-case report, French Polynesia, December 2013. Euro Surveill 2014;19(9):20720.

64. Gérardin P, Guernier V, Perrau J, et al. Estimating Chikungunya prevalence in La Réunion Island outbreak by serosurveys: two methods for two critical times of the epidemic. BMC Infect Dis 2008;8:99.

65. Naresh Kumar CV, Gopal DV. Reemergence of Chikungunya virus in Indian subcontinent. Indian J Virol 2010; 21(1):8-17.

66. Chusri S, Siripaitoon P, Silpapojakul K, et al. Kinetics of chikungunya infections during an outbreak in southern Thailand, 2008-2009. Am J Trop Med Hyg 2014;90(3): 410-417.

67. Pan American Health Organization. Chikungunya. http:// www.paho.org/hq/index.php?option=com_topics\&view= article\&id=343\&Itemid=40931. Accessed July 31, 2017.

68. Centers for Disease Control and Prevention. Chikungunya virus: symptoms, diagnosis, and treatment. CDC website. Updated April 6, 2016. https://www.cdc.gov/chikungunya/ symptoms/index.html. Accessed July 31, 2017.

69. World Health Organization. Emergencies: the history of Zika virus. http://www.who.int/emergencies/zika-virus/timeline/ en/. Accessed July 31, 2017.
70. Simpson DI. Zika virus infection in man. Trans $R$ Soc Trop Med Hyg 1964;58:335-338.

71. Duffy MR, Chen TH, Hancock WT, et al., Zika virus outbreak on Yap Island, Federated States of Micronesia. $N$ Engl J Med 2009;360(24):2536-2543.

72. World Health Organization. Situation report: Zika virus. WHO website. September 22, 2016. http://www.who.int/ emergencies/zika-virus/situation-report/22-september-2016/ en/. Accessed July 31, 2017.

73. Centers for Disease Control and Prevention. Estimated range of Aedes albopictus and Aedes aegypti in the United States, 2016. CDC website. April 1, 2016. https://www. cdc.gov/zika/pdfs/zika-mosquito-maps.pdf. Accessed July 31, 2017.

74. Centers for Disease Control and Prevention. Microcephaly and other birth defects. CDC website. April 26, 2017. https:/www.cdc.gov/zika/healtheffects/birth_defects.html. Accessed July 31, 2017.

75. World Health Organization. WHO statement on the first meeting of the International Health Regulations (2005) (IHR 2005) Emergency Committee on Zika virus and observed increase in neurological disorders and neonatal malformations. WHO website. February 1, 2016. http://www. who.int/mediacentre/news/statements/2016/1st-emergencycommittee-zika/en/. Accessed July 31, 2017.

76. World Health Organization. Middle East respiratory syndrome coronavirus (MERS-CoV) - Saudi Arabia. WHO website. December 19, 2016. http://www.who.int/csr/don/ 19-december-2016-2-mers-saudi-arabia/en/. Accessed July 31, 2017.

77. Cho SY, Kang JM, Ha YE, et al. MERS-CoV outbreak following a single patient exposure in an emergency room in South Korea: an epidemiological outbreak study. Lancet 2016;388(10048):994-1001.

78. Global Polio Eradication Initiative. Polio this week as of 19 April 2017. http://polioeradication.org/polio-today/polionow/this-week/. Accessed July 31, 2017.

79. World Health Organization. WHO removes Nigeria from polio-endemic list [news release]. WHO website. September 25, 2015. http://www.who.int/mediacentre/news/releases/ 2015/nigeria-polio/en/. Accessed July 31, 2017.

80. Global Polio Eradication Initiative. Status: has never stopped indigenous wild poliovirus (WPV) circulation. 2016. http:// polioeradication.org/where-we-work/nigeria/. Accessed July $31,2017$.

Manuscript received January 8, 2017;

revision returned May 10, 2017;

accepted for publication May 11, 2017.

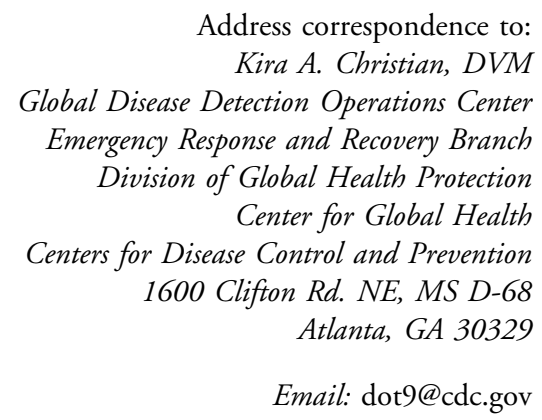

Address correspondence to: Kira A. Christian, DVM Global Disease Detection Operations Center mergency Response and Recovery Branch Global Health Protection Control and Prevention Rd. NE, MS D-68 Email: dot9@cdc.gov 